\title{
Recategorização de unidades de conservação: estudo de caso Reserva Biológica Nascentes da Serra do Cachimbo - PA, Brasil
}

\author{
Recategorization of conservation units: case study Nascentes da Serra do \\ Cachimbo Biological Reserve - PA state, Brazil
}

\section{Tamara Zamadei', Jaqueline de Paula Heimann ${ }^{\text {II }}$, Paulo de Tarso de Lara Pires ${ }^{\text {III }}$}

\begin{abstract}
Resumo
O objetivo central do presente estudo foi analisar a constitucionalidade, assim como os prós e contras de uma possível recategorização da Reserva Biológica Nascentes da Serra do Cachimbo, no Estado do Pará, para atender os critérios de desenvolvimento sustentável: economicamente viável, socialmente justo, e ambientalmente adequado. Verificou-se que é possível a alteração de categoria de uma UC de Proteção Integral, desde que por meio de Lei e compatível aos fins propostos pelo artigo 225 da Constituição Federal. As categorias que se pretende criar pelo PL no Senado 258/2009 e PL de Conversão 4/2017 são compatíveis com o uso e ocupação do solo, em vista disso, os prejuízos trazidos com a consolidação das novas Unidades de Conservação seriam mínimos quando comparados com o desenvolvimento sustentável que seria viabilizado na regiã̃o. No entanto, somente estudos técnicos são capazes de confirmar se a área realmente enquadra-se nas novas categorias, o que garantiria adequação na forma de preservação da natureza.
\end{abstract}

Palavras-chave: Alteração de categoria; Reserva Biológica; Sistema Nacional de Unidades de Conservação

\begin{abstract}
This study aimed to analyze the constitutionality, as well as the pros and cons of a possible recategorization of the Nascentes da Serra do Cachimbo Biological Reserve, located in the state of Pará state, in order to meet the criteria of sustainable development: economically viable, environmentally suitable and socially just. It was verified that it is possible to change the category of an Integral Protection Conservation Unit, provided that it is enacted by Law and compatible with the purposes from article 225 of the Federal Constitution. The categories to be created by Bills No. 258/2009 and 4/2017 are compatible with the soil use and occupation; given this the damages brought with the consolidation of the new Conservation Units would be minimal when compared with the sustainable development that would be feasible in the region. However, only technical studies can confirm whether the area really fits into the new categories, which would guarantee adequacy in the ways of nature conservation.
\end{abstract}

Keywords: Category change; Biological Reserve; National System of Nature Conservation Units

Engenheira Florestal, Dra., Rua das Avencas, 988, Setor Residencial Sul, CEP 78550-067, Sinop (MT), Brasil. tamarazamadei@gmail.com (ORCID: 0000-0001-7341-2514)

II Engenheira Florestal e Advogada, MSc., Av. Prefeito Lothário Meissner, 632, Jardim Botânico, CEP 80210-170, Curitiba (PR), Brasil. jaquelineheimann@gmail.com (ORCID: 0000-0003-1466-7829)

III Engenheiro Florestal e Advogado, Pós-Doutor, Professor Associado, Universidade Federal do Paraná, Setor de Ciências Agrárias, Rua dos Funcionários, 1540, Juvevê, CEP 80030-050, Curitiba (PR), Brasil. ptlpires@gmail.com (ORCID: 0000-0001-9260-540X) 


\section{Introdução}

De acordo com o SFB - Serviço Florestal Brasileiro (2019), a área ocupada por florestas está estimada em 500 milhões de hectares de florestas nativas e 10 milhões de hectares de plantadas, ou seja, $5.100 .000 \mathrm{~km}^{2}$, que equivalem a $60 \%$ da área total do país.

Diante deste contexto de riqueza natural tornou-se cogente a criação de um sistema que garantisse a proteção, com vistas à manutenção da diversidade biológica, ao passo que também assegurasse o desenvolvimento sustentável. Nesta conjuntura é publicada no ano de 2000 a Lei 9.985, que logo se popularizou como SNUC - Sistema Nacional de Unidades de Conservação da Natureza, um dos modelos mais avançados do mundo em se tratando de conservação do ambiente natural (MMA, 2011).

O SNUC busca proteger as áreas naturais de florestas nativas dividindo-as em dois grupos: Proteção Integral e Uso Sustentável, sendo que esses grupos ainda se separam em diferentes categorias. As UCs - Unidades de Conservação são áreas geográficas com relevantes características naturais, que recebem regime de administração especial, ao qual se aplicam garantias de proteção, são instituídas pelo Poder Público através de instrumentos legais e seus limites são bem estabelecidos e delimitados (BRASIL, 2000).

Uma das categorias de UCs é a REBIO - Reserva Biológica. De acordo com a legislação, a REBIO tem como principal objetivo a preservação integral da biota e demais atributos naturais que existam em seu território. Na REBIO não é admitida a intervenção humana direta ou mesmo alterações do ambiente, permitindo-se apenas medidas voltadas a recuperar ecossistemas que já haviam sido alterados ou então ações de manejo essenciais para recuperar e preservar os processos ecológicos naturais, o equilíbrio natural e a biodiversidade.

As UCs de Proteção Integral suportam grandes pressões em seus limites decorrentes do avanço da urbanização e da agricultura. Dentre as REBIOs existentes no território nacional, destaca-se aqui a RBNSC - Reserva Biológica Nascentes da Serra do Cachimbo, que se encontra na região Norte do Brasil, especificamente no Estado do Pará. Foi instituída por meio de um Decreto em 20 de maio do ano de 2005. Compreende parte dos municípios de Novo Progresso e Altamira e possui área total de 342.192 hectares inteiramente no bioma Amazônia.

Mesmo após quase quinze anos da edição do Decreto que cria a RBNSC, muitos proprietários de terras ainda não foram indenizados, e cerca de 200 famílias ainda habitam o interior da REBIO, subsistindo da pecuária e da produção comercial de arroz, banana, abacaxi, café, dentre outras culturas.

É neste contexto de conflitos de interesses quanto à ocupação de terras protegidas, que emerge o debate sobre a recategorização de Unidades de Conservação. Sendo assunto de inúmeros projetos de lei, dentre os quais destaca-se o PLS no 258 de 2009 e o PLV 4/2017 (oriundo da MP 756/2016) que abordam a mudança de categoria da RBNSC para admitir a proteção dos recursos naturais e o uso sustentável sem afetar a comunidade que atualmente encontra-se na UC.

A previsão para alteração na categoria de UC encontra respaldo nos parágrafos 5ำ e $6^{\circ}$ do art. 22 da Lei no 9.985/2000, no entanto, abre precedentes para discussões quanto à constitucionalidade e viabilidade de tomadas de decisão. Em vista disso, o objetivo do presente artigo foi analisar a constitucionalidade, assim como os prós e contras de uma possível alteração de categoria da RBNSC, visando atender os critérios de desenvolvimento sustentável, quais sejam: economicamente viável, socialmente justo e ambientalmente adequado. 


\section{Desenvolvimento}

\section{Reserva biológica}

A categoria de UC Reserva Biológica já estava prevista na Lei 4.771/65, Código Florestal. É uma das UCs com regime mais restritivo do grupo de Proteção Integral, sendo considerada como um "santuário ecológico". A primeira REBIO a ser criada no Brasil foi no ano de 1974, chamada Poço das Antas, no Estado do Rio de Janeiro (MACIEL, 2009; LEUZINGER, 2010).

A Lei do SNUC, no art. 10, apresentou a definição de Reserva Biológica como sendo área de preservação total da biota e outras características naturais presentes em seus limites, não sendo permitida interferência do homem, salvo quando necessárias medidas de recuperação de ecossistemas anteriormente modificados ou ações de manejo para preservar e recuperar o equilíbrio natural, os processos ecológicos e a diversidade biológica (BRASIL, 2000).

Ainda no artigo 10 da Lei encontram-se os seus objetivos e restrições: a REBIO é de posse e domínio públicos, de modo que particulares serão desapropriados; não é permitida visitação, a menos que seja com objetivo educacional; é permitida na REBIO pesquisa científica, desde que autorizada previamente pelo órgão responsável pela administração da mesma.

À luz do Direito Positivo brasileiro, desapropriação é o "procedimento pelo qual o Poder Público, fundado em necessidade, utilidade pública ou interesse social, compulsoriamente despoja alguém de certo bem, adquirindo-o para si, mediante indenização prévia, justa e pagável em dinheiro" (MELLO, 2009, p.858).

A probabilidade de que ocorram desapropriações surge do princípio de que o interesse público é superior, seja pela utilidade pública ou pelo interesse social. A declaração expropriatória é, nesses casos, requisito precedente à transferência da propriedade privada para o domínio público, tal declaração possui prazo de caducidade - por interesse social: dois anos, por utilidade pública: cinco anos (IRIGARAY, 2004).

Ainda no art. 45 da Lei do SNUC restam excluídas indenizações referentes à regularização fundiária das UCs, derivadas ou não de desapropriação, as espécies arbóreas declaradas imunes de corte pelo Poder Público; as áreas que não tenham prova de domínio inequívoco e anterior à criação da Unidade; expectativas de ganhos e lucro cessante; bem como o resultado de cálculo efetuado mediante a operação de juros compostos.

A indenização justa, prévia e em dinheiro é devida, pois a propriedade privada situada nos limites de uma REBIO a ser criada sofrerá esvaziamento de qualquer possibilidade futura de utilização econômica, e ainda o esvaziamento da propriedade privada propriamente dita (MACIEL, 2009).

Em que pese não haver obrigatoriedade de consulta pública para a implementação de

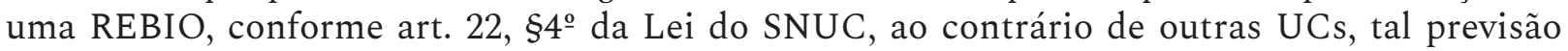
legal vai de encontro com o princípio constitucional da participação e pode dificultar a criação da nova UC. A consulta pública possibilita o entrosamento entre a população local e o órgão executor proponente ao proporcionar uma troca de informações, demonstrando as implicações para a comunidade residente tanto no interior quanto no entorno da UC (MACIEL, 2009).

\section{REBIO Nascentes da Serra do Cachimbo}

A REBIO Nascentes da Serra do Cachimbo foi instituída por meio de Decreto em 20 de maio de 2005, encontra-se em parte dos municípios de Novo Progresso e de Altamira, ambos no Estado do Pará, seu principal objetivo é preservar os ecossistemas naturais que ali existem, permitindo pesquisas científicas e atividades controladas de educação ambiental (BRASIL, 2005). A RBNSC possui Plano de Manejo e Conselho Consultivo estabelecidos, respectivamente, por meio das Portarias $\mathrm{n}^{\circ}$ 76, de 03 de setembro de 2009 e ${ }^{\circ}{ }^{86}$, de 07 de novembro de 2009. 
A REBIO em questão é uma UC de Proteção Integral Federal, administrada do ICMBio - Instituto Chico Mendes de Conservação da Biodiversidade (Figura 1). Integrante do SNUC, representa uma das estratégias nacionais para dar cumprimento aos compromissos, tratados e acordos multilaterais firmados entre o Brasil e outros países na busca de soluções para as questões relacionadas ao meio ambiente global (MMA, 2009).

Em que pese sua importância, a região de estudo permanecia virtualmente desconhecida e intocada até o início da década de 1950, especialmente pela dificuldade de acesso. Sua topografia acidentada, com rios encachoeirados, tornava inviável a navegação e o acesso fluvial à região, que não possuía outros meios de comunicação com as áreas mais povoadas do Estado por via terrestre (MMA, 2006).

Atualmente, a única forma terrestre de chegar à RBNSC é a BR-163 Cuiabá-Santarém. Da divisa do Mato Grosso com o Pará, até o início dos seus limites, percorre-se cerca de $20 \mathrm{~km}$. São $187 \mathrm{~km}$ da sede do município de Novo Progresso até os limites da Reserva, já a partir de Altamira são 985 km (MMA, 2009).

A RBNSC foi concebida dentro do contexto do Programa BR-163 Sustentável, que culminou na criação de um mosaico de UCs, totalizando 6,8 milhões de hectares, que objetivam "fomentar a produção florestal madeireira e não madeireira em bases sustentáveis, ordenar as atividades garimpeiras e assegurar a preservação do meio ambiente” (BRASIL, 2006).

Figura 1 - Localização da Reserva Biológica Nascentes da Serra do Cachimbo - PA, Brasil.

Figure 1 - Location map of the Nascentes da Serra do Cachimbo Biological Reserve - PA state, Brazil.

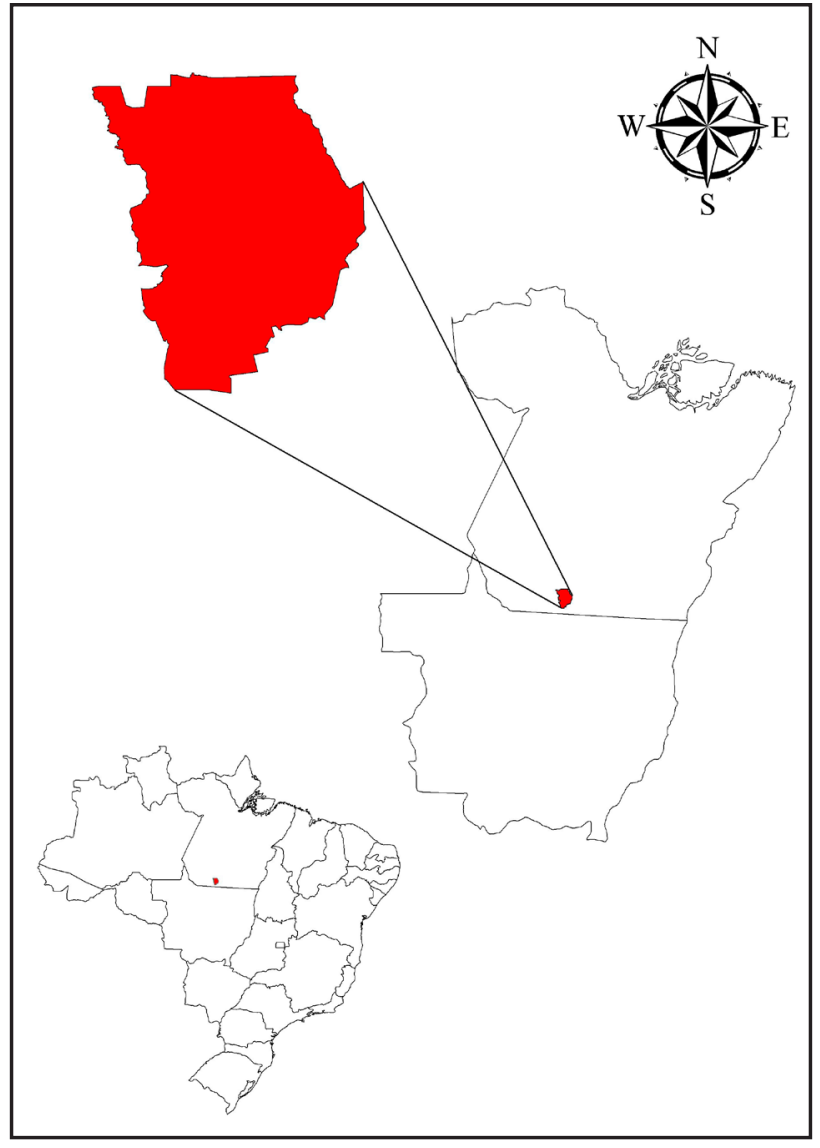

Fonte: Autores (2019)

Source: Authors (2019) 
Segundo a Portaria $n^{\circ}$ 258, de 17 de abril de 2017, passa a ser competência da Unidade Especial Avançada do ICMBio a gerência, manutenção da integridade ambiental, promoção do desenvolvimento sustentável e execução, monitoramento e avaliação de ações da RBNSC, juntamente com outras UCs.

\section{Histórico dos marcos legais}

O Plano de Manejo da RBNSC, elaborado pelo Ministério do Meio Ambiente em parceria com o Instituto Centro de Vida (ICV) e também a ONG WWF Brasil, tornado público em 2009, afirma que alguns eventos foram primordiais para a criação da UC (MMA, 2009).

No ano de 2000 foi desenvolvida a proposta "Espaços do Futuro - Corredor de Conservação da Biodiversidade da Amazônia Meridional” pelo ICV e a Fundação Ecológica Cristalino, tal proposta objetivava consolidar áreas de proteção já existentes, bem como criar novas UCs para frear o desmatamento do Norte de Mato Grosso; no ano de 2002 é criado o protocolo do Plano Integrado de Destinação (PID) das Glebas Curuaés e Cachimbo pela Associação de Produtores Rurais do Vale do XV, em área total de 639 mil hectares, propunha a criação de nove "reservas ecológicas", que somariam 119 mil hectares, onde se localiza a maior parte das nascentes da região (MMA, 2009).

Já em 2005, no Macrozoneamento do Estado do Pará, a área dessas nascentes foi recomendada para se tornar uma Unidade de Conservação de Uso Sustentável. Em fevereiro do mesmo ano o ICV deu início ao projeto "Estabelecimento de Programa Local de Conservação e Estudo de Criação de Unidade de Conservação na Área das Nascentes”, realizando o diagnóstico ambiental e socioeconômico da área, bem como contatos com órgãos ambientais competentes e a comunidade local, que se mostrou receptiva à proposta de criação de uma UC em parte dessa área. O projeto foi levado ao MMA, restando acordado que o diagnóstico da área das nascentes seria utilizado para subsidiar o processo de criação da UC (MMA, 2009).

Uma proposta foi apresentada ao MMA para a criação de duas unidades de conservação: um Parque Nacional dentro de uma Área de Proteção Ambiental. Em maio de 2005, o Governo Federal, por meio de Decreto do Presidente da República, criou a Reserva Biológica (MMA, 2009).

No contexto estadual, a RBNSC representa a categoria cujo manejo de uso é o mais restritivo entre as estabelecidas pelo SNUC, uma das poucas REBIOs do estado do Pará (três federais e uma estadual) e a única na área de influência da BR-163 (BRASIL, 2006).

\section{Caracterização ambiental e socioeconômica}

Com área superior a 300 mil hectares, a REBIO possui grande importância ambiental, principalmente por proteger centenas de nascentes perenes que formam rios das bacias do Xingu e do Tapajós. A denominação "Serra do Cachimbo" é devido à geomorfologia da região, uma vez que a Reserva está localizada no Complexo do Cachimbo, formado pelo conjunto de uma serra e uma chapada. Tal complexo geomorfológico possui evidência na região por apresentar as maiores cotas altimétricas, chegando a $743 \mathrm{~m}$, em que as altitudes não costumam ultrapassam os 200 metros (BRASIL, 2006).

A região da RBNSC compreende o polígono formado por parte dos municípios de Guarantã do Norte e Novo Mundo, no Mato Grosso, além dos distritos de Cachoeira da Serra e Castelo dos Sonhos (representando o município de Altamira) e parte do município de Novo Progresso, no Pará (ao longo do eixo sul da rodovia BR-163); bem como as áreas naturais protegidas: Terras Indígenas Panará e Menkragnoti, Floresta Nacional Jamanxim, Parque Estadual do Cristalino e Campo de Provas Brigadeiro Velloso (BRASIL, 2006).

Até a década de 1970 a área pertencia às Forças Armadas Brasileiras. A Aeronáutica ocupou a área que fica a oeste da BR-163 e o Exército e a Marinha se responsabilizaram pela extensão a leste, que coincide com a área da REBIO (MMA, 2006). 
A paisagem da região da RBNSC sofreu transformações constantes, decorrentes do desflorestamento, estando entre as dez UCs federais mais desmatadas em toda a região da Amazônia Legal (MMA, 2006; ISA, 2017). Até o ano de 2009, cerca de 6\% da Reserva havia sido transformada em pastagem, atividade que, além do desmatamento, desencadeia queimadas, abertura de estradas e de infraestrutura, introdução de espécies exóticas e assoreamento de rios (MMA, 2009).

Cerca de 700 diferentes espécies vegetais e centenas de espécies animais, até mesmo mamíferos silvestres ditos como de estimação por moradores locais, foram identificados durante estudos de elaboração do Plano de Manejo. Destas, há pelo menos três espécies que encontramse sob ameaça de extinção, pois só houve registros pontuais de suas presenças, como o araçaride-pescoço-vermelho (Pteroglossus bitorquatus), a arara-azul-grande (Anodorhynchus hiacinthinus) e a águia-cinzenta (Harpyhaliaetus coronatus), fato este que corrobora com a importância de se manterem preservados os limites territoriais da REBIO (BRASIL, 2006; MMA, 2009).

Atualmente na RBNSC é possível identificar os seguintes sistemas de ocupação e entorno da rodovia BR-163 (MMA, 2009): agricultura familiar de subsistência; exploração de madeira em núcleos urbanos, com inúmeras serrarias; especulação de terras, que acelerou muito a partir do ano de 2000 pela esperança de que a rodovia até Santarém seria asfaltada; exploração agropecuária em grandes propriedades, por meio da formação de fazendas de gado.

Em 2006 o IBAMA, em conjunto com o Instituto Centro de Vida e a ONG WWFBrasil, elaborou relatório com a trajetória da maioria dos posseiros residentes na área, marcada pela luta de apropriação do ambiente natural e sua produtividade. O ambiente, portanto, é entendido como reserva de patrimônio a ser apropriado por quem atue sobre a área e o explore economicamente. Grande parte da infraestrutura encontrada no local, como redes de energia e pontes, foi implantada com recursos próprios dos ocupantes da região.

\section{Desapropriação e indenização da área}

A transformação da área de ricas nascentes em Reserva Biológica, sem a realização de consulta pública, criou certa tensão na região, especialmente quanto à solução dos conflitos de uso da terra e a continuidade de estudos que já estavam previstos ou mesmo em andamento. Os órgãos envolvidos na criação da REBIO desenvolveram atividades com vistas a se chegar em acordo entre as partes, no entanto algumas situações conflitantes ocorreram neste ínterim (MMA, 2006).

Houve acordo entre a população local e os órgãos ambientais em 2006 para a realização de um cadastro com objetivo de levantar quantas famílias e residentes havia nos limites da REBIO, além de traçar o perfil social e econômico destes e de suas posses. Porém, meses depois os produtores rurais optaram por não se cadastrar e em setembro do mesmo ano a Associação de Produtores Rurais Vale do XV impetrou MS - Mandado de Segurança contra a criação da Reserva, argumentando que a UC estava em desconformidade com o resultado de estudo elaborado pelo Governo Estadual, denominado Plano Integrado de Destinação (PID), de 2002, o qual realizou diagnóstico social e econômico da região afetada. Entretanto, o MS não foi acolhido pelo STF Supremo Tribunal Federal, sob argumento de que o IBAMA não identificou nenhum ocupante da RBNSC como proprietário ou pertencente à população tradicional.

Em 2014, em Reunião Extraordinária da Comissão de Meio Ambiente, Defesa do Consumidor e Fiscalização e Controle, levantou-se a questão da indenização dos moradores da RBNSC como um dos principais entraves no estabelecimento da UC (SENADO FEDERAL, 2014). Tal situação ainda se encontra pendente de solução, corroborando a manutenção dos conflitos de interesse entre os moradores e governo. 


\section{Recategorização de Unidades de Conservação}

É viável, em termos legais, alterar a categoria de uma UC já criada para outra mais adequada à realidade biológica e cultural que abriga. Esse instrumento é bastante utilizado quando o Estado, por ter criado UCs anteriores à Lei do SNUC sem quaisquer estudos técnicos preliminares, pretende regularizar as categorizadas de acordo com a Lei ora vigente (BARBOSA, 2013; GURGEL JÚNIOR, 2014).

As UCs de Uso Sustentável podem ser transformadas, total ou parcialmente, em UCs de Proteção Integral, desde que por instrumento normativo do mesmo nível hierárquico daquele que a criou, conforme previsto no parágrafo $5^{\circ}$ do art. 22 da Lei do SNUC. Aumentar os limites de uma UC pode ser feito também por instrumento normativo do mesmo nível hierárquico daquele que a criou, nos termos do parágrafo 60 do mesmo dispositivo legal (BRASIL, 2000).

Importante ressaltar que o fato de um espaço territorial especialmente protegido só pode ser alterado ou mesmo suprimido por lei representa uma proteção ao mesmo. Comumente, esses espaços são criados por decreto, que é editado pelo Chefe do Executivo, conforme artigo 84, inciso IV da Constituição Federal de 1988, e, normalmente, para que um decreto seja revogado ou alterado, basta editar e promulgar novo decreto. No entanto, no caso das UCs, faz-se necessária uma lei específica, que deverá seguir todo o processo legislativo constitucionalmente previsto, aprovada em ambas as casas legislativas, para só então ser assinada pelo Chefe do Executivo. Desta forma, modificar um decreto que institua um espaço territorial especialmente protegido é mais difícil do que seria se não houvesse essa proteção oferecida pela Constituição Federal (PEREIRA; SCARDUA, 2008).

Este pré-requisito constitucional possui intuito de assegurar maior controle dos atos do administrador, controle ampliado esse que se entendeu dispensável contra atos de criação de UCs, uma vez que contra estes bastaria o próprio exercício, pelo proprietário que se sinta lesado, das ações civis tradicionais, colocadas à sua disposição pelo ordenamento jurídico (BENJAMIN, 2001).

A Lei do SNUC no art. 22, §5º , dispõe expressamente que as Unidades de Conservação de Uso Sustentável podem ser transformadas em Unidades de Conservação de Proteção Integral, porém, não há previsão legal para a situação inversa, ou seja, uma UC de Proteção Integral ser transformada em UC de Uso Sustentável.

Neste contexto, Barbosa (2013) afirma que é necessário desmistificar a ideia de que unidades já decretadas possuem categoria inflexível. Não se apregoa que todas as UCs devam passar por processos de mudança de categoria, mas sim que esta possibilidade existe e deve ser aventada quando necessário.

Fundamental proceder a análise de experiências exitosas de recategorização para que sejam avaliados os aspectos positivos e negativos relacionados a cada caso, buscando compatibilizar o que têm em comum e evitar o que não foi proveitoso.

Amplo debate se iniciou no ano de 2016 perante a aprovação da Medida Provisória 756, que buscava alterar os limites da Floresta Nacional do Jamanxim e também do Parque Nacional do Rio Novo, e criaria a Área de Proteção Ambiental Jamanxim, no sudoeste do Pará. A MP foi vetada em junho de 2017, bem como o Projeto de Lei de Conversão 4/2017 dela proveniente.

\section{Reserva Biológica Nascentes da Serra do Cachimbo - Estudo de caso}

Por vezes, tornar uma área intocada pode gerar luta, principalmente em comunidades tradicionais, pelos seus territórios de pertencimento. Nesse sentido, merece ampla discussão e avaliação a necessidade de proteção de um dado território por meio do estabelecimento de uma UC, bem como a determinação da categoria a qual essa UC pertencerá; tal debate deve ocorrer não só entre governo e ambientalistas, mas fundamentalmente com a sociedade que será direta ou indiretamente afetada pela Unidade (BENJAMIN, 2001). 
Especificamente quanto à RBNSC, a criação de uma UC do tipo mais restritivo entre as doze categorias possíveis na Lei do SNUC, incluiu em seus limites áreas com comunidades organizadas, estruturadas, economicamente ativas, que trabalham com pecuária, lavoura, equinocultura, dentre outras atividades. São mais de 200 famílias, $700 \mathrm{~km}$ de estradas, três turbinas para geração de energia, cerca de 40 mil cabeças de gado e produção comercial de café, banana, arroz, abacaxi, dentre outras culturas (BRASIL, 2009).

Em 2009, frente aos conflitos de interesse, o Senador Flexa Ribeiro apresentou um Projeto de Lei no Senado - PLS no 258/2009 objetivando alterar a categoria das UCs de Reserva Biológica para Parque Nacional Nascentes da Serra do Cachimbo e Área de Proteção Ambiental Vale do XV (Figura 2).

Figura 2 - Mapa de alteração de categorias da Reserva Biológica Nascentes da Serra do Cachimbo - PA propostas pelo PLS no 258/2009 e PLV 4/2017.

Figure 2 - Category change map of the Nascentes da Serra do Cachimbo Biological Reserve PA state, proposed by Bills No. 258/2009 and 4/2017.

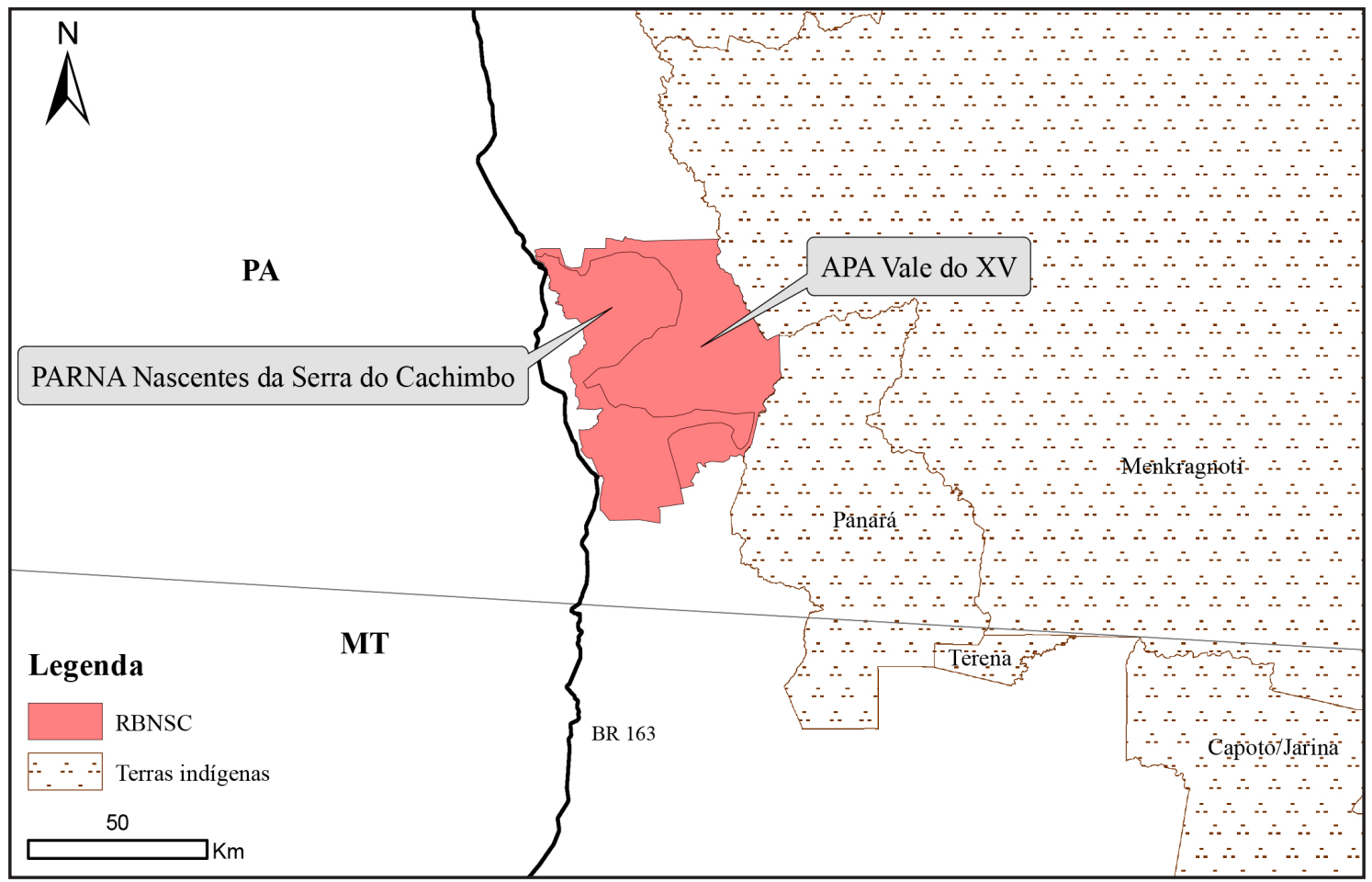

Fonte: Modificado de ISA (2017)

Source: Modified from ISA (2017)

A Lei do SNUC, 9.985/2000, estabelece que a categoria Parque Nacional possui objetivo básico de preservação de ecossistemas naturais de grande relevância ecológica e relevante beleza cênica, com possibilidade de se realizarem pesquisas de cunho científico, atividades de educação e interpretação ambiental, de recreação em contato direto com a natureza, além do turismo ecológico. Também integrante do grupo das UCs de Proteção Integral, é de posse e domínio públicos, o que leva à necessidade de desapropriação daquelas áreas pertencentes à particulares (BRASIL, 2000).

Já a APA - Área de Proteção Ambiental constitui o grupo das UC de Uso Sustentável, e é uma área geralmente extensa, que possui um grau de ocupação humana, dotada de atributos 
abióticos, bióticos, estéticos ou culturais especialmente importantes para a qualidade de vida e o bem-estar das populações humanas; seu principal objetivo é proteger a biodiversidade, organizar o processo de ocupação e assegurar a sustentabilidade do uso dos recursos naturais (BRASIL, 2000).

A proposta de recategorização da RBNSC se baseia no fato de que as áreas de importância ecológica já são vigiadas, respeitadas e conservadas pelos residentes locais. Para o Senador Flexa Ribeiro, que apresentou o Projeto, "somente podem compor os limites de uma Reserva Biológica os locais onde a natureza íntegra, intocada, possa ser preservada o que, por si só, justifica a alteração da categoria” (BRASIL, 2008).

Segundo o INPE - Instituto Nacional de Pesquisas Espaciais (2017), dos $3.422 \mathrm{~km}^{2}$ de área da UC, o total em floresta no ano de 2016 era somente $1.302,95 \mathrm{~km}^{2}$, equivalente a aproximadamente $38 \%$ da área total (Figura 3).

Figura 3 - Imagem de satélite da Reserva Biológica Nascentes da Serra do Cachimbo - PA, datada de 30 de dezembro de 2016.

Figure 3 - Satellite image of the Nascentes da Serra do Cachimbo Biological Reserve - PA state, dated December 30th, 2016.

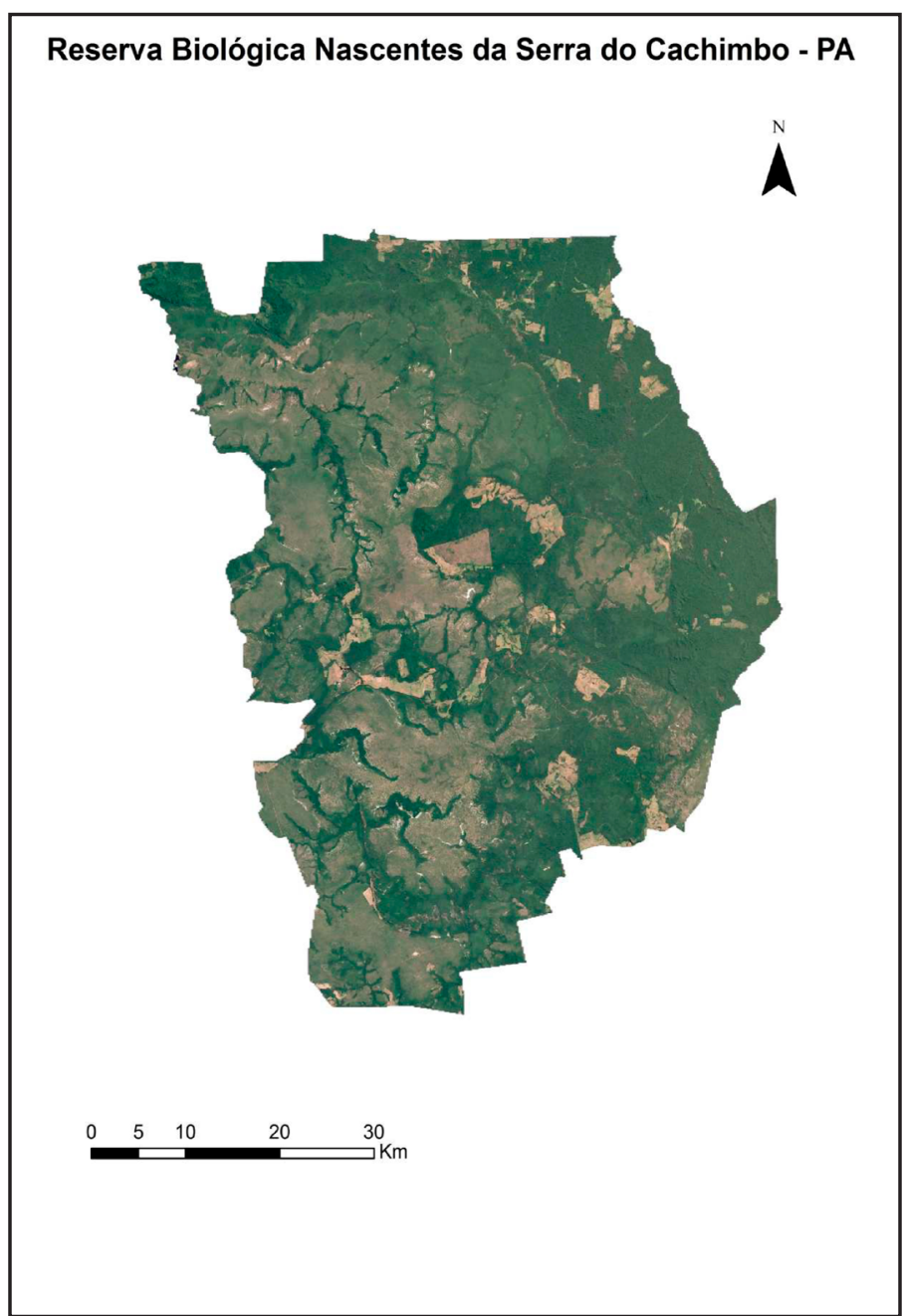

Fonte: Modificada de Google Earth (2019)

Source: Modified from Google Earth (2019) 
No ano de 2009, o então Senador Valdir Raupp votou de forma favorável ao Projeto de Lei por entender que estava conforme normas do processo legislativo e não feria qualquer preceito constitucional, garantia a proteção dos recursos naturais, além de contribuir para o avanço na melhoria das condições e perspectivas de vida da população que foi atraída para a Amazônia por iniciativas do Governo Federal. O Senador afirmou ainda que "a criação do Parque Nacional e a implantação da Área de Proteção Ambiental evitará o deslocamento da população local de suas comunidades, onde estão organizadas e desenvolvem suas atividades produtivas" (SENADO FEDERAL, 2017).

Naquele mesmo ano de 2009, o PLS foi aprovado pela CDR - Comissão de Desenvolvimento Regional e Turismo, sendo no ano seguinte devolvido pelo Relator, Sen. Cícero Lucena com relatório favorável à matéria e às emendas n. 1 e 2-CDR propostas anteriormente pelo Senador Valdir Raupp, além de três novas emendas. No ano de 2011, o voto do Sen. Pedro Taques foi pela rejeição do projeto, sem prejuízo de que, oportunamente, fossem realizados estudos e diligências para averiguar a possibilidade de alteração da RBNSC em Parque Nacional e Reserva Extrativista ou Reserva de Desenvolvimento Sustentável. Atualmente o PL está em tramitação na CMA, tendo como relator atual o Senador Paulo Rocha, na data de 27/04/2017.

Já em 2017, a proposta de recategorização da área da RBNSC foi inclusa no PLV no 4, porém, o mesmo foi revogado conforme citado anteriormente. O MMA manifestou-se pelo veto do referido projeto alegando que as alterações propostas modificariam o regime de proteção das UCs, podendo comprometer e fragilizar a preservação ambiental em uma região sensível da Amazônia Legal, e que parte dos dispositivos do PVL eram inconstitucionais no aspecto formal, por configurar situação de impertinência temática ao objeto inicial da Medida Provisória (BRASIL, 2017a).

Ao longo desses 11 anos, a região viu tanto a ampliação da conservação da floresta em área antropizada há décadas, quanto o aumento da invasão humana, por atividades econômicas não legalizadas, em área de floresta nativa. E os conflitos ambientais na área não cessaram, nem mesmo diminuíram, com a implementação do Projeto da BR-163 e a criação e/ou ampliação das UCs (GUIMARÃES, 2017).

Evidente que existem pontos positivos e negativos com relação à recategorização da RBNSC. Segundo o PLS, a criação da APA Vale do XV comporia uma área de 162 mil ha, caracterizada por grande antropização, a qual geraria a possibilidade do gerenciamento conjunto dos locais que já apresentam processo de ocupação consolidado, garantindo a liberdade de circulação e as atividades rurais. O Parque Nacional Nascentes da Serra do Cachimbo foi eleito para 178 mil ha por suas características naturais, de modo que a população local considera adequado seu estabelecimento, sinalizando clara contribuição para atingir os objetivos da preservação aliada ao desenvolvimento.

Os demais benefícios apontados no PLS são que duas UCs, geram mais empregos para a conservação e administração, além de serem mantidos aqueles dos produtores, que podem manter viva a esperança de uma vida melhor; uma política de consenso que fortalece os princípios democráticos e promove a harmonia social; o dinheiro público é mais bem aplicado, deixando de ser necessárias algumas desapropriações de áreas produtivas e que não apresentam elementos significativos à preservação; mantêm-se o modo de vida, as tradições, a ordem social e econômica, os empregos e as fontes de renda da região, beneficiando as pessoas (BRASIL, 2009).

Necessário considerar os riscos ambientais envolvidos no processo de alteração, especialmente com relação à criação da APA, que pertence ao grupo de UCs de Uso Sustentável, e com isso permite a presença humana na área para o desenvolvimento de atividades que vão além do turismo. Poder-se-iam citar as ameaças à natureza decorrentes da antropização, no entanto, a UC aqui estudada já se encontra alterada pela presença humana como já citado.

Com relação ao Parque Nacional, existem aspectos positivos e negativos trazidos pelas atividades turísticas. Os riscos a serem considerados são a destruição da vegetação, erosão de 
trilhas, lixo, além de ameaças como danos que afetam a evolução dos ecossistemas, alteram o comportamento da fauna e/ou induzem a sua migração. Os aspectos positivos a serem considerados são: educação ambiental, lazer em contato com a natureza, geração de receitas para a UC e de renda para a população local (LEUZINGER, 2010).

Para minimização dos riscos ambientais é fundamental que haja planejamento. Tendo em vista que na criação de uma UC a categoria em que se enquadrará deve possuir o regime jurídico mais condizente com a área a ser protegida, e que as atividades que viabilizam essa decisão baseiam-se em estudos técnicos e consulta pública, entende-se que os riscos ambientais advindos deste ato e de sua implementação encontram-se implícitos e previamente analisados.

Por fim, imperioso ressaltar que o Decreto que cria a RBNSC foi oficialmente publicado no DOU - Diário Oficial da União na data de 23 de maio de 2005 e o estudo técnico sobre o "Estabelecimento de Programa Local de Conservação e Estudo de Criação de Unidade de Conservação na Área das Nascentes da Serra do Cachimbo”, foi apresentado alguns meses depois, em 30 de setembro do mesmo ano.

\section{Considerações finais}

A Lei do SNUC, em total conformidade com a Constituição da República Federativa do Brasil de 1988, permite que seja realizada recategorização de uma UC de Proteção Integral para UC de Uso Sustentável, desde que realizada por meio de lei, não decreto, e que esta alteração seja compatível com os fins determinados pelo artigo 225 da Carta Maior.

Com relação ao estudo efetivo da RBNSC, as categorias de Unidades de Conservação Área de Proteção Ambiental (de uso sustentável) e Parque Nacional (de proteção integral) que se pretende criar são perfeitamente compatíveis com os usos e ocupação do solo existentes, uma vez que a região possui áreas intensamente antropizadas e áreas completamente preservadas pela comunidade local.

Em vista disso, os prejuízos que podem advir com a implementação das novas categorias de UCs seriam mínimos frente ao desenvolvimento sustentável que seria viabilizado na região.

Finalmente, é preciso considerar que somente estudos técnicos são capazes de confirmar se a área enquadra-se nas novas categorias, assim garantindo adequação na forma de preservação da natureza.

\section{Agradecimentos}

Ao Programa de Educação Continuada em Ciências Agrárias e Ambientais (PECCA) da Universidade Federal do Paraná, pela concessão de bolsa à primeira autora para realização do curso de Pós-Graduação em Direito Ambiental.

\section{Referências}

BARBOSA, C. S. Recategorização de unidades de conservação: o discurso de uma nova territorialidade e participação social no contexto do Parque Nacional dos Pontões Capixabas ES. 2013. 167 f. Dissertação (Mestrado em Geografia) - Universidade Federal de Minas Gerais, Instituto de Geociências, Belo Horizonte, 2013.

BENJAMIN, A. H. de V. e. O regime brasileiro de unidades de conservação. Revista de Direito Ambiental, São Paulo, v. 6, n. 21, p. 27-56, 2001.

BRASIL. Lei n 9.985, de 18 de julho de 2000. Regulamenta o art. 225, § $1^{\circ}$, incisos I, II, III e VII da Constituição Federal, institui o Sistema Nacional de Unidades de Conservação da Natureza e dá outras providências. Diário Oficial da União, Poder Executivo, Brasília, DF, 19 jul. 2000. Seção 1, p. 1. 
BRASIL. Decreto $\mathrm{s} / \mathrm{n}$, de 20 de maio de 2005. Dispõe sobre a criação da Reserva Biológica Nascentes da Serra do Cachimbo, no Estado do Pará, e dá outras providências. Diário Oficial da União, Poder Executivo, Brasília, DF, 23 mai. 2005. Seção 1, p. 8.

BRASIL. Plano de Desenvolvimento Regional Sustentável para a Área de Influência da Rodovia BR-163 Cuiabá - Santarém. Brasília: Casa Civil - GT Interministerial, 2006.

BRASIL. Lei Ordinária ${ }^{\circ}$ 11686, de 02 de junho de 2008. Altera a Categoria da Unidade de Conservação Parque Nacional dos Pontões Capixabas para Monumento Natural dos Pontões Capixabas, nos Municípios de Pancas e Águia Branca, no Estado do Espírito Santo. Diário Oficial da República Federativa do Brasil, Poder Executivo, Brasília, DF, 3 jun. 2008. Seção 1, p. 2.

BRASIL. Projeto de Lei do Senado ${ }^{\circ}$ 258, de 2009. Altera a categoria da unidade de conservação Reserva Biológica Nascentes da Serra do Cachimbo para Parque Nacional Nascentes da Serra do Cachimbo e Área de Proteção Ambiental Vale do XV, nos Municípios de Altamira e Novo Progresso, no Estado do Pará. Disponível em: http://www25.senado.leg.br/web/atividade/ materias/-/materia/91668. Acesso em: 02 mar. 2017.

BRASIL. Medida Provisória no 756, de 19 de dezembro de 2016. Altera os limites do Parque Nacional do Rio Novo, da Floresta Nacional do Jamanxim e cria a Área de Proteção Ambiental do Jamanxim. Diário Oficial da União, Poder Executivo, Brasília, DF, 20 dez. 2016. Seção 1, p. 2.

BRASIL. Projeto de Lei de Conversão no 4, de 11 de abril de 2017. Altera os limites da Floresta Nacional do Jamanxim, cria a Área de Proteção Ambiental do Jamanxim, altera a categoria da unidade de conservação Reserva Biológica Nascentes da Serra do Cachimbo para Parque Nacional Nascentes da Serra do Cachimbo e Área de Proteção Ambiental Vale do XV, e altera os limites do Parque Nacional de São Joaquim, assim como seu nome para Parque Nacional da Serra Catarinense. Ofício n. 200 (CN), Brasília, DF, 18 abr. 2017a. Disponível em: http://www. camara.gov.br/proposicoesWeb/prop_mostrarintegra?codteor $=1546189 \&$ filename $=$ PLV+4/2017+ MPV75616+\%3D\%3E+MPV+756/2016. Acesso em: 20 fev. 2018.

BRASIL. Portaria no 258, de 17 de abril de 2017. Define as unidades de conservação federal compreendidas pela Unidade Especial Avançada nos termos do art. 20 do Decreto no 8.974, de 24 de janeiro de 2017. Diário Oficial da União, Brasília, DF, 18 abr. 2017b. Seção 1, p. 92.

GOOGLE. Google Earth. Version PRO. 2017. Disponível em: https://www.google.com.br/intl/ pt-PT/earth/ad. Acesso em: 01 set. 2017.

GUIMARÃES, A. Solução de conflitos ambientais ou conflito de soluções legislativas: O caso das medidas provisórias nos 756 e 758, de 2016. Boletim Legislativo, n. 62, 2017.

GURGEL JÚNIOR, F. J. Aspectos legais da recategorização de uma unidade de conservação - o caso do Parque Natural Municipal Fazenda Santa Cecília do Ingá (Volta Redonda/RJ). Cadernos UniFOA, Volta Redonda, n. 24, 2014.

INSTITUTO NACIONAL DE PESQUISAS ESPACIAIS. Desflorestamento nas Unidades de Conservação da Amazônia Legal. Área de Floresta da Reserva Biológica Nascentes da Serra do Cachimbo. 2017. Disponível em: http://www.dpi.inpe.br/prodesdigital/atruc.php?ID=147\&ano=2 017\&esfera=Federal\&. Acesso em: 14 mai. 2019.

INSTITUTO SOCIOAMBIENTAL - ISA. Rebio Nascentes da Serra do Cachimbo. 2017. Disponível em: https://uc.socioambiental.org/uc/4768. Acesso em: 02 mar. 2017.

IRIGARAY, C. T. J. H. Aspectos constitucionais da proteção de unidades de conservação. In: FIGUEIREDO, Guilherme José Purvin de (coord). Direito ambiental em debate. v. 2. Rio de Janeiro: Esplanada, 2004.

LEUZINGER, M. D. Uso Público em Unidades de Conservação. In: CONGRESSO DO MAGISTÉRIO SUPERIOR DE DIREITO AMBIENTAL DA APRODAB E CONGRESSO DE

Ci. Fl., Santa Maria, v. 29, n. 4, p. 1796-1808, out./dez. 2019 
DIREITO AMBIENTAL DA PUC-RIO, 8., 1.,2010, Rio de Janeiro. Anais... Rio de Janeiro: PUC, 2010. p. 1-19.

MACIEL, M. da S. P. Criação e implantação das Reservas Biológicas. 2009. 78 f. Trabalho de Conclusão de Curso (Graduação) - Departamento de Direito, Pontifícia Universidade Católica do Rio de Janeiro, Rio de Janeiro, 2009.

MELlo, C. A. B. de. Curso de Direito Administrativo. 26. ed. São Paulo: Malheiros, 2009. 1102 p.

MINISTÉRIO DO MEIO AMBIENTE. Reserva Biológica Nascentes da Serra do Cachimbo: caracterização biótica, física, socioeconômica e avaliação ecológica rápida. 2006. 175 p.

MINISTÉRIO DO MEIO AMBIENTE. Plano de Manejo da Reserva Biológica Nascentes da Serra do Cachimbo. Brasília, 2009. Disponível em: http://www.icmbio.gov.br/portal/images/ stories/imgs-unidades-coservacao/rebio_nascentes_da_serra_do_cachimbo.pdf. Acesso em: 02 mar. 2017.

MINISTÉRIO DO MEIO AMBIENTE. Dez anos do Sistema Nacional de Unidades de Conservação da Natureza: lições do passado, realizações presentes e perspectivas para o futuro. Brasília: MMA, 2011. 220 p.

PEREIRA, P. F.; SCARDUA, F, P. Espaços territoriais especialmente protegidos: conceito e implicações jurídicas. Ambiente e sociedade, Campinas, v. 11, n. 1, p. 81-97, 2008.

SENADO FEDERAl. Ata da 14ํㅡㄹ Reunião Extraordinária da Comissão de Meio Ambiente, Defesa do Consumidor e Fiscalização e Controle, da 4 ${ }^{a}$ Sessão Legislativa Ordinária da 54 ${ }^{-a}$ Legislatura. 2014. Disponível em: http://www19.senado.gov.br/sdleg-getter/public/ getDocument?docverid=a39a827f-21d8-44fa-8433-3ab76f464b44;1.1. Acesso em: 02 mar. 2017.

SENADO FEDERAL. Pauta da 35 ${ }^{\mathbf{a}}$ Reunião Extraordinária da Comissão de Meio Ambiente, Defesa do Consumidor e Fiscalização e Controle, da $1^{\underline{a}}$ Sessão Legislativa Ordinária da 55 ${ }^{a}$ Legislatura. 2015. Disponível em: http://legis.senado.leg.br/sdleg-getter/ documento/ download/98d046ed-841c-4cd8-a766-692300541c41. Acesso em: 02 mar. 2017.

SERVIÇO FLORESTAL BRASILEIRO. Boletim SNIF 2018 Ed. 1. 2019. Disponível em: http:// www.florestal.gov.br/documentos/publicacoes/4092-boletim-snif-2018-ed1/file. Acesso em: 01 jun. 2019. 